\title{
Computer-Controlled Milk Feeding of Dairy Calves: The Effects of Number of Calves per Feeder and Number of Milk Portions on Use of Feeder and Social Behavior
}

\author{
M. B. Jensen \\ Department of Animal Health and Welfare, Danish Institute of Agricultural Sciences, \\ Research Centre Foulum, 8830 Tjele, Denmark
}

\begin{abstract}
One hundred ninety-two calves (Holstein-Friesian, Danish Red, and Jersey) were allocated to either groups of 24 calves or groups of 12 calves with one computer-controlled milk feeder per group. Within group, one-half of the calves were offered the daily milk allowance in either 4 or 8 milk portions. In groups with 24 calves, there was a higher level of competition for access to the feeder than in groups with 12 calves. Calves waited longer for access, and while occupying the feeder, they were more often disturbed by other calves attempting to access the feeder. The increased level of competition resulted in a higher rate of milk ingestion among calves in groups of 24 and, as a result, a lower duration of time spent ingesting the milk and a lower occupation of the feeder per calf. The number of calves per feeder did not affect the amount of milk ingested, but the high level of disturbance and the increased feeding rate with 24 calves per feeder suggest that these calves were subject to social constraint. Offering the same milk allowance in 4 rather than 8 milk portions lowered the occupancy of the feeder. The number of portions did not affect the duration of ingesting milk, but the duration of occupying the feeder just after milk ingestion was lower with 4 than with 8 milk portions. Thus, fewer and larger portions may lower competition for access during the activity periods if all other factors remain equal.
\end{abstract}

(Key words: calf, feeding method, feeding behavior, social behavior)

\section{INTRODUCTION}

The trend in dairy production is a move toward larger production units and group housing of animals of all age groups. Group housing of calves during the milk feeding period poses special problems because it

Received February 12, 2004.

Accepted May 5, 2004.

E-mail: MargitBak.Jensen@agrsci.dk. may be difficult to ensure the milk intake of an individual calf unless computer-controlled milk feeders are used. However, computer-controlled milk feeders represent a costly investment, and often farmers have only one feeding stall for a group of $>20$ calves to make the system more economically viable. The question then becomes whether 20 or 30 calves per milk feeder results in a high level of competition for access to the feeder and social pressure on the calves. Previous research may suggest that it does. For instance, with 26 calves per feeder, the calves waited up to $1 \mathrm{~h}$ daily for access (Morita et al., 1999). Furthermore, problems with cross-sucking, a redirection of the natural sucking behavior toward other calves, may be intensified by competition for access to the feeder. Therefore, the first aim of the present study was to investigate the effect of number of calves per computer-controlled milk feeder (12 vs. 24 calves per feeder) on use of the feeder by calves, competition between the calves for access to the feeder, and milk intake and weight gain of calves.

When computer-controlled milk feeders are used, the daily milk allowance is typically made accessible to the calves in several portions between 0.5 and $2 \mathrm{~L}$. Often there are time lags of 20 to 120 min between the accessibility of successive milk portions (Bøe and Havrevoll, 1993). In addition to these rewarded visits, the calves may pay visits to the feeder where no milk is accessible to them, i.e., unrewarded visits. A high level of unrewarded visits to the milk feeder has been found in several studies where calves were offered many small milk portions from computer-controlled milk feeders (Bøe and Havrevoll, 1993; Morita et al., 1999). Unrewarded visits may result in the disturbance of calves already feeding, and they may block the milk feeder for calves waiting for a rewarded visit. A high number of calves per feeder may increase the number of unrewarded visits, thereby exacerbating the problem. One suggested reason for many unrewarded visits is that it is an attempt to get more milk because of hunger, as increasing the milk allowance from 5 to $8 \mathrm{~L} / \mathrm{d}$ reduced by half the duration of unrewarded visits in calves fed by a computer-controlled 
milk feeder (Jensen and Holm, 2003). Another reason for unrewarded visits may be that the calves have difficulties in predicting when milk is accessible to them. This may be easier when a given milk allowance is divided between fewer and larger portions. Finally, sucking is stimulated by the ingestion of milk (de Passillé et al., 1992; Rushen and de Passillé, 1995), and the more frequent stimulation of the sucking motivation may also result in calves occupying the feeder for longer periods on a daily basis. Therefore, the second aim of the present study was to investigate the effect of the number of milk portions at a given milk allowance on the calves' use of the feeder, competition between the calves for access to the feeder, and their milk intake and weight gain.

\section{MATERIALS AND METHODS}

\section{Animals, Housing, and Feeding}

One hundred ninety-two calves were used in the experiment. One hundred eighteen calves were male $(\mathrm{n}=56)$ and female $(\mathrm{n}=62)$ calves born during 2002 at the Danish Cattle Research Center at Foulum. These calves were Holstein-Friesian ( $\mathrm{n}=46)$, Danish Red $(\mathrm{n}=54)$, or Jersey $(\mathrm{n}=18)$. Seventy-four HolsteinFriesian male calves were born at the Danish Institute of Agricultural Sciences at Research Center Foulum also during 2002. These calves were transported to the Danish Cattle Research Center in a light vehicle with closed sides when they were 1 wk old. The 2 research centers are placed only a few kilometers apart. For the purpose of this particular experiment, a special permission to transport the calves before they were 2 wk of age was granted by the Danish Ministry of Justice.

All calves were housed with their dam in a large straw-bedded pen for 1 to $2 \mathrm{~d}$ after birth and were then moved to either individual straw-bedded calf hutches $(1.75 \times 1.10 \mathrm{~m})$ with an outdoor yard $(1.60 \times 1.00 \mathrm{~m})$ or individual straw-bedded indoor pens $(1.95 \times 0.9 \mathrm{~m})$. Here, the calves were fed milk via teat buckets. They were fed colostrum until d 5 ; from $\mathrm{d} 5$ to 8 , they received whole milk; and from d 9 to 12 , milk replacer $(60 \%$ skimmed milk powder) gradually replaced whole milk. The calves were moved to an experimental barn with computer-controlled feeders when they were $12 \mathrm{~d}$ old. However, the first calves of each block were not moved until a minimum of 2 calves were old enough to be moved to a pen at the same time. Until the calves were gradually weaned off milk between d 64 and 70, they were offered a daily milk allowance as specified previously. In addition to the milk replacer, the calves were offered concentrates and hay ad libitum from $d$ 12 and throughout the experimental period.
The experimental barn had 6 sections. In one-half of these sections, there were 2 straw-bedded pens ( 4.65 $\times 4.35 \mathrm{~m}$ ) each with room for 12 calves. In the other one-half of the sections, there was only one large straw bedded pen $(9.30 \times 4.35 \mathrm{~m})$ for 24 calves. All pens had one milk feeder equipped with one teat and connected to a computer-controlled unit (HL100; Calvex, Højslev, Denmark).

The calves were allocated to treatments in blocks. Each of 6 blocks included 24 calves (blocks 1, 2, 3, 8, 9, and 10). Each of Blocks 1, 3, 8, and 10 were allocated to a section with one pen for a group of 24 calves; each of Blocks 2 and 9 were allocated to a section with 2 pens, each for one group of 12 calves. Within Blocks 2 and 9 , the calves were allocated to one of the 2 groups balanced with respect to age, breed, and sex. In Blocks $1,2,3,8,9$, and 10 , the mean age was $31 \mathrm{~d}(\mathrm{SD}=10.3)$ at the start of the data collection. Because of seasonal variation in calving, the intermediate 4 blocks (Blocks $4,5,6$, and 7) only included 12 calves, each to obtain a similar standard deviation of age within the blocks. In these blocks, the mean age at the start of the data collection was $30 \mathrm{~d}(\mathrm{SD}=9.5)$, and calves were all allocated to pens for 12 calves. Therefore, the data set included 4 groups with 24 calves per milk feeder and 8 groups with 12 calves per milk feeder. Within each group, the calves were allocated to one of the 2 additional treatments balanced with respect to age, breed, and sex. These 2 treatments distributed the daily milk allowance into either 4 or 8 portions. The milk allowance for calves of the Holstein-Friesian and the Danish Red breeds was $6.4 \mathrm{~L} / \mathrm{d}$, and the milk allowance for calves of the Jersey breed was $6.4 \mathrm{~L} / \mathrm{d}$ (Blocks 1 , 2 , and 3) or $5.2 \mathrm{~L} / \mathrm{d}$ (remaining blocks). The calves offered $6.4 \mathrm{~L} / \mathrm{d}$ were offered this milk ration in either 4 portions of $1.6 \mathrm{~L}$ or 8 portions of $0.8 \mathrm{~L}$. Similarly, the Jersey calves offered $5.2 \mathrm{~L} / \mathrm{d}$ had either 4 large portions (1.2 and $1.4 \mathrm{~L})$ or 8 small portions $(0.6$ and $0.8 \mathrm{~L}$ ). Thus, the 4 experimental treatments were 1) 12 calves per feeder and 4 milk portions 2) 12 calves per feeder and 8 milk portions, 3) 24 calves per feeder and 4 milk portions, and 4) 24 calves per feeder and 8 milk portions.

\section{Data Collection and Statistical Analyses}

Data were collected via the computer-controlled milk feeder. The computer program controlling the milk feeder divided each $24-\mathrm{h}$ period into two 12 -h feeding periods. The feeding periods of the individual calves started between 0500 and $0900 \mathrm{~h}$ and between 1700 and $2100 \mathrm{~h}$, respectively. The calves were allocated at random to start their feeding period within this range. The range in start of feeding period is stan- 
dard for the type of computer-controlled milk feeders used, as this was thought to minimize queuing at the feeder. Within each 12 -h feeding period, the calves were offered one-half of their daily milk allowance in either 2 or 4 milk portions, according to treatment. The calves could take their first milk portion when a new 12-h feeding period started. At least $30 \mathrm{~min}$ had to pass between successive milk portions. If a calf consumed $<0.2 \mathrm{~L}$ of a portion, the intake was not recorded, and the calf was allowed to receive the whole portion later. If a calf consumed $>0.2 \mathrm{~L}$ of a portion but less than the allowance per portion, then the remaining milk could be consumed in an additional milk portion. Had the calf not consumed its ration within the 12-h feeding period, a maximum of $1 \mathrm{~L}$ would be transferred to the next 12 -h feeding period. From the day after the youngest calf of each block had been introduced and for the next $14 \mathrm{~d}$, the data collected from the computer-controlled milk feeder unit were logged onto a separate computer. At the start of the data collection, the calves' ages ranged from 13 to $57 \mathrm{~d}$, which means that, for some calves, gradual weaning was initiated during the last one-half of the data collection period.

The computer-controlled milk feeder unit recorded the start and end time of 3 different types of visits to the feeder: rewarded visits, unrewarded visits, and visits during which the calf had access to milk but did not consume any. Rewarded visits, visits during which the calf had milk in the feeder, included time spent ingesting milk (defined by the presence of milk in the mixer bowl) and time spent in the feeder just after ingesting milk (after the mixer bowl had been emptied). Finally, milk intake was recorded for each rewarded visit. Data obtained from days when the feeder had been out of order because of technical problems were deleted from the data set. For each calf and each day, the number and duration of the 3 types of visits were calculated. Furthermore, the duration of all visits to the feeder, the duration of ingesting milk during rewarded visits, the milk intake, and the duration of time spent in the feeder after ingesting milk were calculated for each calf and each day. Finally, the rate of ingestion was calculated as the milk intake divided by the duration of ingesting milk. For each of the variables, an average across days within each of the $2 \mathrm{wk}$ following the introduction of the youngest calf was calculated for each calf, and this was used as input data in the statistical analyses.

Some of the variables were transformed by the square root (duration of all visits, number and duration of rewarded visits, duration of ingesting milk, and number and duration of unrewarded visits) or by natural logarithm (number and duration of visits during which the calf had access to milk but did not con- sume any) to meet the assumption of normal distribution of the data. Data were analyzed by variance component analysis (Littell et al., 1996). The statistical model included the effect of number of calves per feeder (12 or 24 ), number of milk portions (4 or 8 per $24 \mathrm{~h}$ ), number of calves per feeder $\times$ number of milk portions, breed, sex, week, number of calves per feeder $\times$ week, number of portions $\times$ week, number of calves per feeder $\times$ breed, number of portions $\times$ breed, number of calves per feeder $\times$ sex, and number of milk portions $\times$ sex as fixed effects. Pen was included as a random effect in the model to take into account the dependence between the calves housed in the same pen. The correlation between repeated observations of the same individual was modeled as compound symmetry. Satterthwaite's approximation was used to calculate the denominator degrees of freedom (Littell et al., 1996). Age of calf at the start of the data collection was included as a covariate in the analysis of variables, where the $P$ value for this factor was $<0.20$ (number of visits during which the calf had access to milk but did not consume any, number of rewarded visits, rate of ingesting milk, time spent after ingesting milk, and milk intake).

\section{Data Collected Using Video Recorder}

One 24-h time lapse video recording (starting at $0800 \mathrm{~h}$ ) was made for each block of calves when the youngest calf in the block was at least $3 \mathrm{wk}$ old and before the gradual weaning of the oldest calf was completed at $d 70$. Based on the videotapes, the behavioral categories described in Table 1 were recorded by focal animal sampling using continuous recording. Two people conducted the behavioral recordings. The number and duration of each of the behavioral categories per observation day were calculated.

The effects of number of calves per feeder and number of milk portions on the duration of "lying," "occupying feeder alone," "occupying feeder not alone," and "waiting for access to feeder," as well as the frequency of "entering feeder as soon as it is free," "attempts to access occupied feeder," and "displace other calf" were analyzed by variance component analysis. The statistical model included the effect of number of calves per feeder (12 or 24), number of milk portions (4 or 8 per $24 \mathrm{~h}$ ), number of calves per feeder $\times$ number of milk portions, breed, sex, number of calves per feeder $\times$ breed, and number of portions $\times$ breed as fixed effects. As a random effect, the model included pen. Satterthwaite's approximation was used to calculate the denominator degrees of freedom (Littell et al., 1996). Before analysis, "waiting for access to feeder" was transformed by natural logarithm, and "entering feeder as soon as it is free," "attempts to access occu- 
Table 1. Description of the recorded behaviors.

\begin{tabular}{|c|c|}
\hline Behavior & Description \\
\hline Lying & $\begin{array}{l}\text { Lying on the lower hind legs and thighs, abdomen } \\
\text { and front legs, or lying on one side }\end{array}$ \\
\hline Occupying feeder, alone & Standing in the milk feeder sucking on the teat or inactivity \\
\hline Occupying feeder, not alone & $\begin{array}{l}\text { Standing in the milk feeder sucking on the teat or inactivity, } \\
\text { while another calf attempts to access the feeder (see description below) }\end{array}$ \\
\hline \multicolumn{2}{|r|}{ 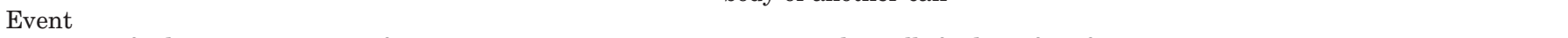 } \\
\hline Entering feeder as soon as it is free & $\begin{array}{l}\text { Entering the milk feeder, often from a waiting position next to } \\
\text { it, at the same moment that another calf leaves the feeder }\end{array}$ \\
\hline Attempt to access occupied feeder ${ }^{1}$ & $\begin{array}{l}\text { Entering the milk feeder parallel to another calf that is already occupying } \\
\text { the feeder or pushing the head with force against the body of another calf } \\
\text { occupying the milk feeder; also, placing the chin on the body of another } \\
\text { calf occupying the feeder }\end{array}$ \\
\hline
\end{tabular}

${ }^{1}$ The identity of the attempted displaced or displaced calf is recorded.

pied feeder," and "displace other calf" were square roottransformed to meet the assumption of normal distribution of the data. Preliminary analyses showed that the interactions sex $\times$ number of milk portions, and sex $\times$ number of calves per feeder were not significant for any of the variables $(P>0.20)$. Therefore, these interactions were not included in the model. Preliminary analyses also showed that there was no effect of observer for any of the variables, and this effect was not included in the analyses either.

Many calves did not perform "cross-sucking;" 25\% of the calves performed "cross-sucking" for $>3 \mathrm{~min} / 24$ $\mathrm{h}$. Therefore, this variable was transformed into binary variables before analysis. Within breed, the hypothesis of no difference in the distribution of calves that never performed "cross-sucking," as well as calves that performed "cross-sucking" for $>3 \mathrm{~min} / 24 \mathrm{~h}$, between the 2 group sizes was tested using the $\chi^{2}$ test or by the Fisher exact test (Siegel and Castellan, 1988).

Finally, the duration of "lying," the duration of "total time occupying the feeder," and the proportion of feeder visits in each of the $24 \mathrm{~h}$ (duration of visit in each hour divided by the duration of visits on a 24$\mathrm{h}$ basis) were calculated for each calf and hour. The proportion of feeder visits in each of the $24 \mathrm{~h}$ was analyzed by a model including number of calves per feeder (12 or 24), hour, and number of calves per feeder $\times$ hour as fixed effects. As a random effect, the model included pen.

\section{Data for BW and BW Gain}

The calves were weighed at birth, at introduction into the group at $\mathrm{d} 12$, and every $14 \mathrm{~d}$ thereafter until they had completed the gradual weaning at $d 70$. For each individual, a straight line was fitted between successive data points, and BW at d 26, 40, 54, and 68 was extrapolated. Based on these data, the daily BW gain in each of the 4 periods (d 13 to 26,27 to 40,41 to 54 , and 55 to 68 ) was calculated. The data for daily BW gain and BW were analyzed by a model including the effect of number of calves per feeder (12 or 24), number of milk portions ( 4 or 8 per $24 \mathrm{~h}$ ), number of calves per feeder $\times$ number of milk portions, breed, sex, period, number of calves per feeder $\times$ period, number of milk portions $\times$ period, number of calves per feeder $\times$ breed, number of milk portions $\times$ breed, number of calves per feeder $\times$ sex, and number of milk portions $x$ sex as fixed effects. As a random effect, the model included pen. Furthermore, birth BW corrected for breed and sex (by subtracting the mean birth BW within breed and sex from the birth BW) was included as a covariate in the analysis for daily BW gain. The correlation between repeated observations on the same individual was modeled as auto regressive correlation of first order. Satterthwaite's approximation was used to calculate the denominator degrees of freedom (Littell et al., 1996).

One Danish Red calf in Block 5 had to be removed from the pen because of a poor leg and was excluded from both the computer-collected data and the videocollected data. Three calves (2 Holstein-Friesians [Blocks 6 and 8] and one Danish Red [Block 6]) had to be excluded from the data collected via the computercontrolled milk feeder because of disease during the data collection period. Three calves from Block 10 (2 Holstein-Friesians plus one Danish Red) had to be 
Table 2. Main effect of number of calves per feeder on variables collected via the computer-controlled milk feeder.

\begin{tabular}{|c|c|c|c|c|}
\hline & \multicolumn{2}{|c|}{ Calves per milk feeder } & \multirow[b]{2}{*}{$F$} & \multirow[b]{2}{*}{$P$} \\
\hline & 12 & 24 & & \\
\hline & $\longrightarrow \mathrm{Me}$ & $\mathrm{SE} \longrightarrow$ & & \\
\hline \multicolumn{5}{|l|}{ Duration $(\mathrm{min} / 24 \mathrm{~h})$} \\
\hline All visits & $36.50 \pm 1.33$ & $30.43 \pm 1.34$ & $\mathrm{~F}_{1,23.8}=10.08$ & $=0.004$ \\
\hline Rewarded visits & $22.84 \pm 0.73$ & $18.51 \pm 0.71$ & $\mathrm{~F}_{1,20.9}=17.50$ & $<0.001$ \\
\hline Milk ingestion & $18.40 \pm 0.75$ & $13.03 \pm 0.79$ & $\mathrm{~F}_{1,12.7}=23.08$ & $<0.001$ \\
\hline After milk ingestion & $3.58 \pm 0.46$ & $5.05 \pm 0.69$ & & NS \\
\hline Unrewarded visits & $6.67 \pm 1.12$ & $7.96 \pm 1.53$ & & NS \\
\hline With access, no milk & $3.46 \pm 0.55$ & $2.35 \pm 0.50$ & & NS \\
\hline Rate of ingestion $(\mathrm{L} / \mathrm{min})$ & $0.301 \pm 0.017$ & $0.397 \pm 0.022$ & $\mathrm{~F}_{1,13.6}=11.70$ & $=0.004$ \\
\hline \multicolumn{5}{|l|}{ Number (frequency per $24 \mathrm{~h}$ ) } \\
\hline Rewarded visits & $6.45 \pm 0.36$ & $5.86 \pm 0.48$ & & NS \\
\hline Unrewarded visits & $6.67 \pm 1.12$ & $7.96 \pm 1.53$ & & NS \\
\hline With access, no milk & $5.58 \pm 0.95$ & $4.31 \pm 0.87$ & & NS \\
\hline
\end{tabular}

excluded from the data collected via video because of disease; one Holstein-Friesian from Block 9 was excluded because of a lost transponder on the day of video observation.

The results are presented as means \pm standard errors. Please note that for those variables that were transformed before analysis, the mean and approximate standard errors are back-transformed and presented on the measured scale.

\section{RESULTS}

\section{Data Collected via the Computer- Controlled Milk Feeder}

No effects of treatments on milk intake were found $(5.2 \pm 1.7 \mathrm{~L} / \mathrm{d})$. However, the older the calves were at the start of the data collection, the more milk they ingested $\left(\mathrm{F}_{1,168}=26.52 ; P<0.001\right)$, the higher their rate of ingesting milk $\left(\mathrm{F}_{1,170}=16.98 ; P<0.001\right)$, and the more rewarded visits they had $\left(\mathrm{F}_{1,172}=14.45 ; P\right.$ $<0.001$ ).

Effects of number of calves per feeder. The effects of number of calves per feeder are shown in Table 2. The duration of rewarded visits was shorter among calves in groups of 24 calves with one milk feeder than among calves in groups of 12 calves with one milk feeder, which was due to a shorter duration of milk ingestion for calves in groups of 24 . Thus, the rate of milk ingestion was increased among calves in groups of 24 (Table 2), although this increase was most pronounced in female calves $(0.302 \pm 0.019,0.300 \pm 0.020$, $0.362 \pm 0.023$, and $0.432 \pm 0.026 \mathrm{~L} / \mathrm{min}$ for males and females in groups of 12 and for males and females in groups of 24 calves, respectively; $\mathrm{F}_{1,168}=6.05 ; P=$ $0.02)$. Also, the duration of all visits was shorter among calves in groups of 24 with one milk feeder than among calves in groups of 12 with one milk feeder (Table 2).

The duration of unrewarded visits was shorter among calves in groups of 12 than that among calves in groups of 24 during wk 1 but not during wk 2 (6.18 $\pm 1.12,7.19 \pm 1.20,8.53 \pm 1.62$, and $7.41 \pm 1.51 \mathrm{~min} /$ $24 \mathrm{~h}$ for 12 calves in wk 1,12 calves in wk 2,24 calves in wk 1 , and 24 calves in wk 2 , respectively; $\mathrm{F}_{1,176}=$ 5.49; $P=0.02$ ). Jersey calves had fewer unrewarded visits to the feeder in groups of 12 than in groups of $24(5.11 \pm 1.72,9.73 \pm 1.25,8.88 \pm 1.13,12.04 \pm 2.71$, $6.30 \pm 1.46$, and $9.61 \pm 1.30$ times $/ 24 \mathrm{~h}$ for Jersey, Danish Red, and Holstein-Friesian in groups of 12 and Jersey, Danish Red, and Holstein-Friesian in groups of 24 , respectively; $\mathrm{F}_{2,169}=4.57 ; P=0.01$ ). Male calves had more rewarded visits than female calves in groups of $24(6.66 \pm 0.36,6.30 \pm 0.35,11.16$ \pm 0.60 , and $6.10 \pm 0.49$ times $/ 24 \mathrm{~h}$ for males and females in groups of 12 and males and females in groups of 24 calves, respectively; $\mathrm{F}_{1,167}=4.55 ; P=0.03$ ).

Effects of number of milk portions. The effects of number of milk portions are shown in Table 3. The duration of all visits and of rewarded visits were shorter among calves that were offered their daily ration in 4 portions compared with 8 portions. However, the duration of rewarded visits decreased significantly over the 2 -wk period for calves that were offered 4 portions, but not for calves that were offered 8 portions $(20.21 \pm 0.75,16.45 \pm 0.68,24.23 \pm 0.83$, and $21.99 \pm$ $0.79 \mathrm{~min} / 24 \mathrm{~h}$ for 4 portions in wk 1 and 2 , and 8 portions in wk 1 and 2 , respectively; $\mathrm{F}_{1,184}=4.13 ; P=$ $0.04)$. This interaction was due to a more pronounced increase in feeding rate from wk 1 to 2 in calves offered the milk in 4 portions than in calves offered the milk in 8 portions $(0.339 \pm 0.017,0.405 \pm 0.017,0.308 \pm$ 0.017 , and $0.346 \pm 0.017 \mathrm{~L} / \mathrm{min}$ for 4 portions in wk 1 
Table 3. Main effect of number of milk portions on variables collected via the computer-controlled milk feeder.

\begin{tabular}{|c|c|c|c|c|}
\hline & \multicolumn{2}{|c|}{ Milk portions per $24 \mathrm{~h}$} & \multirow[b]{2}{*}{$F$} & \multirow[b]{2}{*}{$P$} \\
\hline & 4 & 8 & & \\
\hline & $\longrightarrow \mathrm{Me}$ & $\mathrm{SE} \longrightarrow$ & & \\
\hline \multicolumn{5}{|l|}{ Duration $(\min / 24 \mathrm{~h})$} \\
\hline All visits & $30.27 \pm 1.22$ & $36.69 \pm 1.35$ & $\mathrm{~F}_{1,167}=12.95$ & $<0.001$ \\
\hline Rewarded visits & $18.28 \pm 0.66$ & $23.10 \pm 0.73$ & $\mathrm{~F}_{1,168}=24.82$ & $<0.001$ \\
\hline Milk ingestion & $15.03 \pm 0.64$ & $16.18 \pm 0.66$ & & NS \\
\hline After milk ingestion & $2.86 \pm 0.39$ & $6.00 \pm 0.57$ & $\mathrm{~F}_{1,161}=35.71$ & $<0.001$ \\
\hline Unrewarded visits & $7.00 \pm 1.09$ & $7.62 \pm 1.12$ & & NS \\
\hline With access, no milk & $2.72 \pm 0.38$ & $2.98 \pm 0.42$ & & NS \\
\hline Rate of ingestion & $0.372 \pm 0.016$ & $0.326 \pm 0.016$ & $\mathrm{~F}_{1,163}=7.80$ & $=0.006$ \\
\hline \multicolumn{5}{|c|}{ Number (frequency per $24 \mathrm{~h}$ ) } \\
\hline Rewarded visits & $5.02 \pm 0.31$ & $7.45 \pm 0.38$ & $\mathrm{~F}_{1,164}=85.61$ & $<0.001$ \\
\hline Unrewarded visits & $7.00 \pm 1.09$ & $7.62 \pm 1.12$ & & NS \\
\hline With access, no milk & $4.81 \pm 0.77$ & $5.00 \pm 0.81$ & & NS \\
\hline
\end{tabular}

and wk 2 , and 8 portions in wk 1 and 2 , respectively; $\left.\mathrm{F}_{1,181}=4.44 ; P=0.04\right)$. The duration of ingesting milk also decreased more over the 2 -wk period for calves offered 4 portions than for calves offered 8 portions $(16.43 \pm 0.73,13.70 \pm 0.67,16.67 \pm 0.74$, and $15.70 \pm$ $0.72 \mathrm{~min} / 24 \mathrm{~h}$ for 4 portions in wk 1 and 2 , and 8 portions in wk 1 and 2 , respectively; $\mathrm{F}_{1,184}=5.50 ; P=$ 0.02 ). The duration of visits after milk ingestion was longer for calves offered 8 milk portions than 4 milk portions (Table 3), but this difference was most pronounced in Jersey calves ( $3.33 \pm 0.85,2.93 \pm 0.52,2.36$ $\pm 0.36,8.99 \pm 1.39,4.22 \pm 0.60$, and $5.26 \pm 0.56 \mathrm{~min} /$ $24 \mathrm{~h}$ for Jersey, Danish Red, and Holstein-Friesian with 4 portions and Jersey, Danish Red, and HolsteinFriesian with 8 portions, respectively; $\mathrm{F}_{2,162}=3.10 ; P$ $<0.05)$. Furthermore, the difference was most pronounced in female calves $(3.10 \pm 0.47,2.62 \pm 0.47,5.22$ \pm 0.59 , and $6.83 \pm 1.13 \mathrm{~min} / 24 \mathrm{~h}$ for male and female calves offered 4 portions and male and female calves offered 8 portions, respectively; $\mathrm{F}_{2,162}=4.89 ; P=0.03$ ). The number of rewarded visits was shorter when the calves were offered their ration in 4 milk portions (Table 3)

Effects of breed. The duration of all visits was shortest in Danish Red and longest in Jersey calves $(38.26 \pm 2.30,28.94 \pm 1.24$, and $33.32 \pm 1.00 \mathrm{~min} / 24 \mathrm{~h}$, respectively, for Jersey, Danish Red, and HolsteinFriesian; $\left.\mathrm{F}_{2,169}=7.69 ; P<0.001\right)$. Also, the duration of rewarded visits was shortest in Danish Red and longest in Jersey calves $(23.39 \pm 1.24,18.25 \pm 0.67$, and $20.38 \pm 0.54 \mathrm{~min} / 24 \mathrm{~h}$, respectively, for Jersey, Danish Red, and Holstein-Friesian; $\mathrm{F}_{2,171}=7.56 ; P<$ 0.001). The duration of milk ingestion was shorter in calves of the Danish Red breed compared with the calves of the 2 other breeds $(16.84 \pm 1.00,14.05 \pm 0.64$, and $15.99 \pm 0.58 \mathrm{~min} / 24 \mathrm{~h}$, respectively, for Jersey, Danish Red, and Holstein-Friesian; $\mathrm{F}_{2,172}=5.88 ; P=$ $0.003)$, and the rate of ingestion was lower $(0.314 \pm$

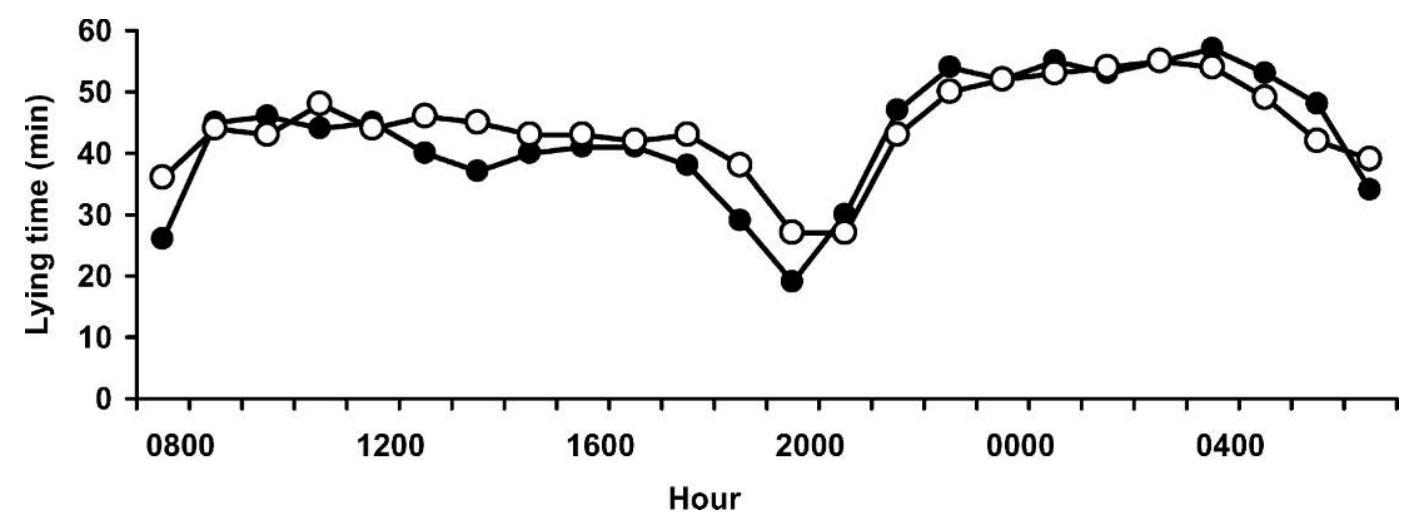

Figure 1. Diurnal distribution of lying (min per calf, each h) for calves in groups with $12(\bigcirc)$ and $24(\bullet)$ per feeder. 
JENSEN

Table 4. Main effect of number of calves per feeder on variables collected via video.

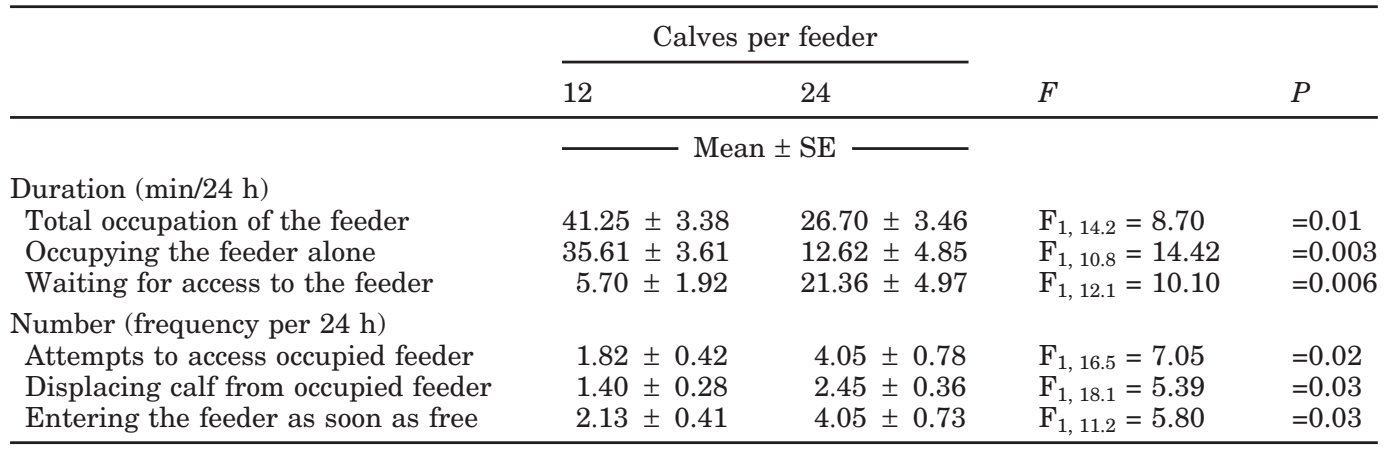

$0.023,0.384 \pm 0.017$, and $0.348 \pm 0.014 \mathrm{~L} / \mathrm{min}$ for Jersey, Danish Red, and Holstein-Friesian, respectively; $\mathrm{F}_{2,169}=4.85 ; P=0.009$ ).

Effects of sex. Male calves took longer ingesting the milk than females $(16.27 \pm 0.61$ vs. $14.96 \pm 0.65$ $\left.\min / 24 \mathrm{~h} ; \mathrm{F}_{1,172}=4.47 ; P=0.04\right)$.

Effects of week. The mean duration of all visits decreased over the 2 -wk period (34.52 \pm 1.03 and 32.31 $\pm 1.01 \mathrm{~min} / 24 \mathrm{~h}$ for wk 1 and $\left.2 ; \mathrm{F}_{1,182}=7.84 ; P=0.006\right)$.

\section{Data Collected from the Video Recordings}

The calves were lying on average $17.4 \pm 1.3 \mathrm{~h} / 24 \mathrm{~h}$, but lying was not affected by treatment, breed, or sex. The diurnal distributions of lying for calves in groups of 12 and 24 are shown in Figure 1.

The duration of time occupying the feeder and the duration of time occupying the feeder alone (i.e., undisturbed by other calves) were shorter among calves in groups of 24 than among calves in groups of 12 (Table 4). On the other hand, the amount of time waiting by the milk feeder and the frequency of "attempts to access occupied feeder," "displacing calf from occupied feeder," and "entering the feeder as soon as it was free" were higher among calves in groups of 24 than among calves in groups of 12 (Table 4).

Calves of the Danish Red breed occupied the feeder less than calves of the other breeds $(38.46 \pm 4.63,28.24$ \pm 2.80 , and $34.43 \pm 2.82 \mathrm{~min} / 24 \mathrm{~h}$ for Jersey, Danish Red, and Holstein-Friesian, respectively; $\mathrm{F}_{2,173}=3.38$; $P=0.04)$. Jersey calves were more often the victims of attempts to displace a feeding calf from the feeder $(5.68 \pm 0.60,2.74 \pm 0.39,2.74 \pm 0.36$ times per $24 \mathrm{~h}$ for Jersey, Danish Red, and Holstein-Friesian, respectively; $\mathrm{F}_{2,170}=14.97 ; P<0.001$ ) and were more often displaced from the feeder than calves of the other breeds $(4.08 \pm 1.04,2.07 \pm 0.56,2.22 \pm 0.58$ times per $24 \mathrm{~h}$ for Jersey, Danish Red, and Holstein-Friesian, respectively; $\mathrm{F}_{2,170}=5.31 ; P=0.006$ ).

The median duration of cross-sucking per calf was $6 \mathrm{~s} / 24 \mathrm{~h}$ (interquartile range, 0 to $180 \mathrm{~s} / 24 \mathrm{~h}$ ). There were large individual differences between calves regarding the duration of cross-sucking. Ninety-two calves (i.e., 49\%) never performed any cross-sucking; $25 \%$ of the calves performed cross-sucking for $>3 \mathrm{~min} /$ $24 \mathrm{~h}$. The number of calves that never performed cross-

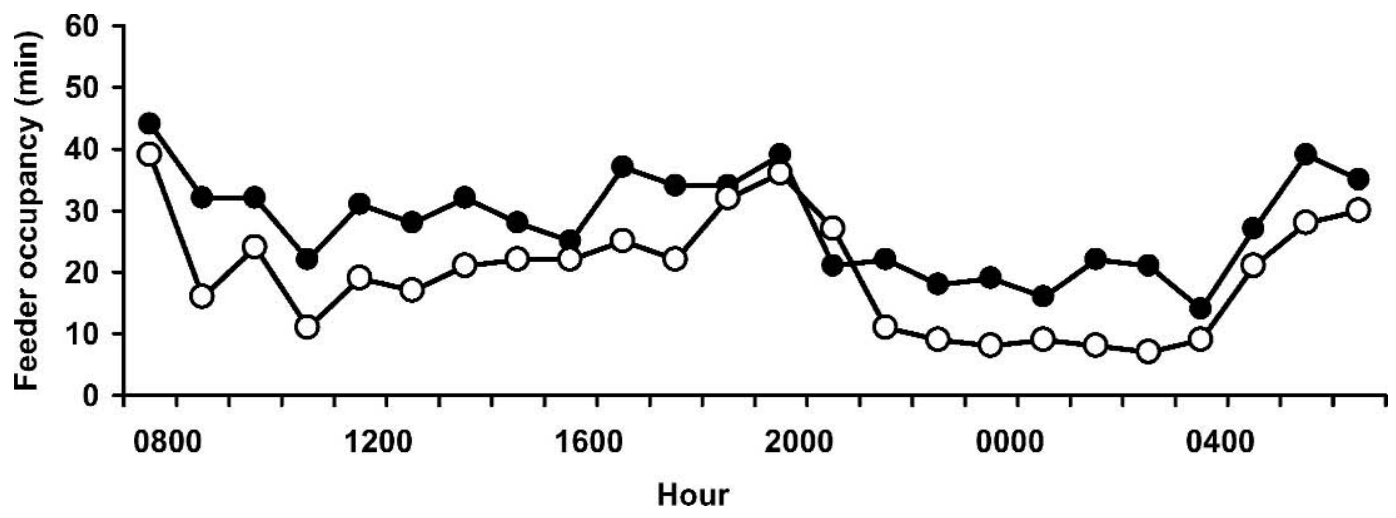

Figure 2. Diurnal distribution of feeder occupancy (min per group, each h) for groups of $12(\bigcirc)$ and $24(\bullet)$ calves per feeder. 


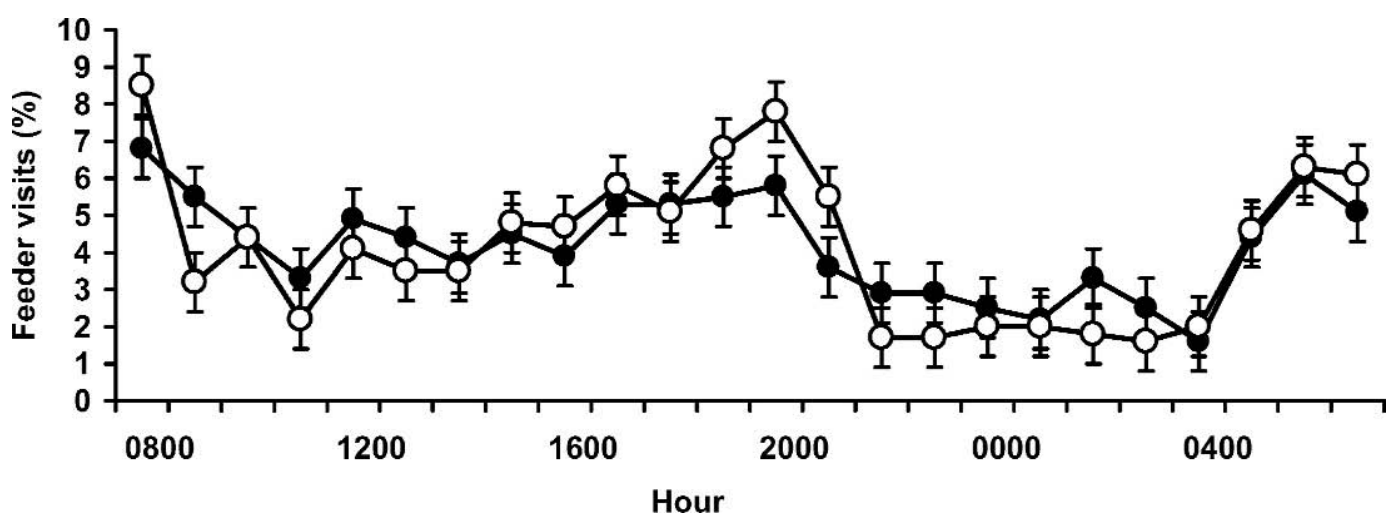

Figure 3. Proportion $( \pm \mathrm{SE})$ of feeder visits (visit each h per visits during $24 \mathrm{~h}$ ) distributed over a 24 -h period for calves in groups with $12(\bigcirc)$ and $24(\bullet)$ per feeder.

sucking and the number of calves that performed cross-sucking for $>3 \mathrm{~min} / 24 \mathrm{~h}$ were not affected by treatment in any of the 3 breeds.

The diurnal distributions of feeder occupancy for groups of 12 and 24 calves are shown in Figure 2. The diurnal distribution of the proportion of feeder visits for calves in groups of 12 and 24 is shown in Figure 3. No significant interaction was found between hour and number of calves for the proportion of feeder visits.

\section{BW Gain}

No effects of treatment were found on live weight gain. The daily weight gain increased with age (514 \pm $28,699 \pm 28,769 \pm 28$, and $869 \pm 28 \mathrm{~g} / \mathrm{d}$ for period 1 , 2,3 , and 4 respectively; $\mathrm{F}_{3,518}=37.00 ; P<0.001$ ) and was lower in calves of the Jersey breed compared with the calves of the other 2 breeds $(630 \pm 47,725 \pm 29$, and $784 \pm 21 \mathrm{~g} / \mathrm{d}$ for Jersey, Danish Red, and HolsteinFriesian, respectively; $\mathrm{F}_{2,250}=5.06 ; P=0.007$ ). The average $\mathrm{BW}$ was $47.2 \pm 1.0,56.4 \pm 1.0,67.5 \pm 1.0$, and $79.5 \pm 1.0 \mathrm{~kg}$ in period $1,2,3$, and 4 , respectively. The average BW was lower in calves of the Jersey breed $(50.3 \pm 2.2,67.9 \pm 1.4$, and $69.9 \pm 1.1 \mathrm{~kg}$ for Jersey, Danish Red, and Holstein-Friesian, respectively; $\mathrm{F}_{2}$, $174=35.73 ; P<0.001)$. The average $\mathrm{BW}$ was higher in male calves $(65.5 \pm 1.2$ and $59.8 \pm 1.3 \mathrm{~kg}$ for male and female calves, respectively; $\mathrm{F}_{2,177}=13.93 ; P<0.001$ ).

\section{DISCUSSION}

In groups with 24 calves and one computer-controlled milk feeder, there was a higher level of competition for access to the feeder than in groups with 12 calves. Calves waited longer for access, and while occupying the feeder, they were more often disturbed by other calves attempting to access the feeder them- selves. This increased level of competition resulted in a higher rate of milk ingestion among calves in groups of 24 and, as a result, a lower duration of time spent ingesting the milk and a lower occupation of the feeder per calf. The number of calves per feeder, however, did not affect the amount of milk ingested or the daily $\mathrm{BW}$ gain.

These effects of a higher level of competition for access to a computer-controlled milk feeder for calves have not been reported previously. However, these results correspond well with studies on the effect of number of ad libitum-fed growing pigs per single-space, computer-controlled concentrate feeder. For instance, pigs occupied the feeder less and ate faster when there were 20 pigs per feeder compared with these values when there were 5,10 , or 15 pigs per feeder (Nielsen et al., 1995), and similar results were found comparing 2, 4, 8, and 12 pigs per feeder (Hyun and Ellis, 2001). Also, less aggression has been reported when there were 10 compared with 20 pigs per feeder (Spoolder et al., 1999).

Nielsen (1999) suggested that the changes in feeding behavior observed in animals housed in groups are expressions of an adaptation to the social environment. She hypothesized that the animals were attempting to obtain a preferred feed intake and a preferred rate of feeding while feeding at specific times of day. Social animals, such as cattle and swine, synchronize feeding and resting, which has evolutionary adaptive value in avoiding predation. When competition for access to feed increases, the animals may adapt to this by feeding at a faster rate than preferred, feeding less than preferred, and by feeding at less preferred times of day. In her review, Nielsen (1999) documented that animals tend to defend a preferred feed intake and feeding at preferred times of day by increasing 
their feeding rate, and she proposed that a change in feeding rate is a good indicator of social constraint. In the present experiment, the calves in groups of $24 \mathrm{did}$ not ingest less milk than the calves in groups of 12 , but they ingested the milk faster. The distribution of feeder occupation over the 24 -h period did not differ, which supports that the calves were reluctant to feed at less preferred times.

Although calves in groups of 24 ingested the milk faster than calves in groups of 12 , they spent the same amount of time in the feeder after milk ingestion. The calves' sucking behavior in the feeder was not recorded, but it is likely that some of the increase in this time reflects an increase in calves sucking on the empty teat after milk ingestion (nonnutritive sucking). The sucking motivation is stimulated by the ingestion of milk, and it declines spontaneously within approximately 10 min (de Passillé et al., 1992; Lidfors, 1993). Assuming that the time occupying the feeder just after milk ingestion reflects nonnutritive sucking, then why was the duration of this activity not affected by the higher level of competition the same way the duration of ingesting milk was? With respect to ingesting milk, the calves were acting as to fulfill their nutritional need and increased their rate of milk ingestion to minimize the risk of having the meal interrupted. With respect to nonnutritional sucking, the calves cannot fulfill their behavioral need by increasing the rate of the behavior. One explanation for why the time occupying the feeder just after milk ingestion was not lower in groups of 24 calves may be that these calves, despite the more disturbances in the feeder, continued to suck on the teat. Although they appeared to defend this activity, the total duration of time with opportunity to suck (total duration of rewarded visits) was nevertheless lower among the calves in groups of 24 .

If the number of calves per feeder had been $>24$, would the calves then have fed more during the afternoon and night hours, or could they have increased their rate of ingesting milk even more? Haley et al. (1998) fed individually housed calves (4 mo old) $5 \mathrm{~L}$ of milk using varying orifice sizes of the milk supply tube $(1.6$ to $5.5 \mathrm{~mm})$ and found that an intake of $1 \mathrm{~L} / \mathrm{min}$ was the maximum rate of ingestion for calves of that age. In the present study, the rate of milk ingestion was measured indirectly, which means that it may not be compared directly with other experiments. The diameter of the milk supply tube was $5 \mathrm{~mm}$, and the calves were only, on average, 1 mo old at the start of the data collection. The rate of ingesting milk was higher the higher the age at the start of the data collection. However, it is possible that calves of this age can only ingest on average $0.4 \mathrm{~L} / \mathrm{min}$, which was the mean ingestion rate among the calves in groups of 24 . If this is the case, then a further increase in the number of calves per feeder could compromise milk intake.

In the present experiment, the group size and the number of calves per milk feeder were confounded. The reason for confounding these 2 factors was that, if the farmer chooses to use more feeders, it seems reasonable to reduce group size instead of having large groups with more feeders per group. For instance, the risk of pneumonia was found to be lower in small groups (Svensson et al., 2003). The positive effects of lowering competition may also be more pronounced in smaller groups. For instance, reducing the number of pigs per drinker from 20 to 10 was more effective in increasing drinking time in groups of 20 than in groups of 60 pigs (Turner et al., 2000).

Offering the same milk allowance in 4 rather than 8 milk portions per $24 \mathrm{~h}$ lowered the occupancy of the feeder by more than $5 \mathrm{~min} / 24 \mathrm{~h}$ per calf. Thus, lowering the number of milk portions may lower competition for access during the activity periods if all other factors remain equal. This lower occupancy per $24 \mathrm{~h}$ was due to a lower duration of rewarded visits when the daily ration was offered in 4 rather than 8 milk portions. However, there was no difference in the duration of milk ingestion per $24 \mathrm{~h}$, and the lower duration of rewarded visits was due to a lower duration of occupying the feeder just after milk ingestion. The level of nonnutritive sucking after milk ingestion has earlier been found to be similar when the calves are given their normal volume and one-half of their normal volume of milk (Rushen and de Passillé, 1995). In the present experiment, the sucking motivation was stimulated twice as many times per day in calves given 8 vs. 4 milk portions. If time occupying the feeder just after milk ingestion reflects nonnutritive sucking, then this explains the increased time spent daily occupying the feeder just after milk ingestion in calves offered 8 milk portions.

The computer-controlled milk feeder was set up to allow the calves to ingest any milk leftovers in an additional milk portion. This appeared to happen frequently among calves offered their milk allowance in 4 portions, as these calves distributed their ration into, on average, 5 milk portions per $24 \mathrm{~h}$. The calves offered 4 portions had some control and could choose to have more and smaller portions; the calves offered 8 portions could not choose to have fewer and larger portions. The appropriate number of milk portions is likely to depend on the milk allowance, and calves may attempt to obtain a preferred amount of milk per portion, rather than a preferred number of portions.

In the present experiment, the $24 \mathrm{~h}$ were divided into two 12-h feeding periods, the first milk portion was available at the beginning of the period, and the 
calves had to wait 30 min between successive portions within a feeding period. This corresponds to 4 and 8 feeding periods, respectively, for calves offered 4 and 8 milk portions. In dairy cows fed restricted amounts of concentrate, increasing the number of feeding periods of a computer-controlled concentrate feeder from four 6-h periods to six 4-h periods increased the number of unrewarded visits as well as the feeder occupancy on a daily basis. The number of unrewarded visits per feeding period was the same, regardless of the number of feeding periods (Livshin et al., 1995), and increasing the number of feeding periods appeared to make it more difficult for the cows to detect when concentrates were available. Similarly, it could be expected that it would have been easier for the calves of the present experiment to detect when they had access to milk if fewer and larger portions had been given. However, this did not appear to be the case, as the number of milk portions did not affect the number or the duration of unrewarded visits. An alternative explanation for unrewarded visits may be that it is difficult to get access to the feeder at appropriate intervals. This would explain the higher level of unrewarded visits in groups with 24 calves and one milk feeder in the first week.

The calves of the Danish Red breed ingested the milk faster than the calves of the other 2 breeds, and this resulted in a lower duration of rewarded visits as well as all visits. Because increased feeding rate indicates social constraint, this could suggest that these calves suffered more from social pressure than calves of the other 2 breeds. However, the behavioral data suggested that the Jersey calves were more socially constrained, as they were more frequently displaced from the feeder than the calves of the HolsteinFriesian and the Danish Red breeds. Calves of the Jersey breed are smaller than calves of the other 2 breeds and are more easily displaced because it is easier to enter the feeder next to them. Furthermore, more calves per feeder increased the number of unrewarded visits only in the Jersey calves, suggesting that these calves had more difficulties in getting access to the feeder at appropriate intervals and in accessing it when they had the right to get milk. The faster rate of ingestion for calves of the Danish Red breed might have been due to other breed differences.

Female calves increased their feeding rate more as a response to a higher number of calves per feeder, which suggests that the female calves were more constrained by the social environment than were male calves. This may be due to the fact that female calves had, on average, a lower BW than did male calves.

It could be expected that a high number of calves per feeder may result in behavioral problems, such as cross-sucking, which is defined as one calf sucking on the body of another calf (de Passillé, 2001). For instance, Bokkers and Koene (2001) reported that crosssucking occurred mainly around the milk feeder and that most cross-sucking was observed within $10 \mathrm{~min}$ after ingesting milk when 40 calves had access to one feeder. However, in the present study, no significant effects of number of calves per feeder were found for either the number of calves that performed cross-sucking or the number of calves that performed cross-sucking for $>3 \mathrm{~min} / 24 \mathrm{~h}$.

In conclusion, the enhanced level of disturbance of feeding calves and the increased feeding rate when there were 24 calves per feeder suggest that these calves were subject to social constraint. Offering milk in fewer and larger portions may lower competition for access during the activity periods if other factors remain equal.

\section{ACKNOWLEDGMENTS}

This study was conducted at the Danish Cattle Research Centre and was funded by the Danish Livestock Federation. Thanks to Kathrine Larsen and Jane Eriksen for managing the calves and to Erik L. Decker and Leif M. Møller for compiling the data that were automatically collected by the computer-controlled milk feeder. Thanks to John Misa Obidah and Gynther M. Nielsen for technical assistance and to Birte Lindstrøm Nielsen and Eva Søndergaard for valuable comments on earlier versions of the manuscript.

\section{REFERENCES}

Bøe, K., and Ø. Havrevoll. 1993. Cold housing and computer-controlled milk feeding for dairy calves: Behavior and performance. Anim. Prod. 57:183-191.

Bokkers, E. A. M., and P. Koene. 2001. Activity, oral behaviour and slaughter data as welfare indicators in veal calves: A comparison of three housing systems. Appl. Anim. Behav. Sci. 75:1-15.

de Passillé, A. M. 2001. Sucking motivation and related problems in calves. Appl. Anim. Behav. Sci. 72:175-187.

de Passillé, A. M., J. H. M. Metz, P. Mekking, and P. R. Wiepkema. 1992. Does drinking milk stimulate sucking in young calves? Appl. Anim. Behav. Sci. 34:23-36.

Haley, D. B., J. Rushen, I. J. H. Duncan, T. M. Widowski, and A. M. de Passillé. 1998. Effects of resistance to milk flow and the provision of hay on nonnutritive sucking by dairy calves. J. Dairy Sci. 81:2165-2172.

Hyun, Y., and M. Ellis. 2001. Effect of group size and feeder type on growth, performance and feeding patterns in growing pigs. J. Anim. Sci. 79:803-810.

Jensen, M. B., and L. Holm. 2003. The effect of milk flow rate and milk allowance on feeding related behavior in dairy calves fed by computer controlled milk feeders. Appl. Anim. Behav. Sci. 82:87-100.

Lidfors, L. 1993. Cross-sucking in group-housed dairy calves before and after weaning off milk. Appl. Anim. Behav. Sci. 38:15-24.

Littell, R. C., G. A. Milliken, W. W. Stroup, R. D. Wolfinger. 1996. SAS System for Mixed Models. SAS Inst., Inc., Cary, NC.

Livshin, N., E. Maltz, and Y. Edan. 1995. Regularity of dairy cow feeding behavior with computer-controlled feeders. J. Dairy Sci. 78:296-304. 
Morita, S., S. Sugita, M. Yamamoto, S. Hoshiba, and T. Uemura. 1999. Behavioral investigation of group rearing calves in automatic milk replacer feeding system. Anim. Sci. J. 70:542-546.

Nielsen, B. L. 1999. On the interpretation of feeding behavior measures and the use of feeding rate as an indicator of social constraint. Appl. Anim. Behav. Sci. 63:79-91.

Nielsen, B. L., A. B. Lawrence, and C. T. Whittemore. 1995. Effects of group size on feeding behavior, social behavior, and performance of growing pigs using single-space feeders. Livest. Prod. Sci. 44:73-85.

Rushen, J., and A. M. de Passillé. 1995. The motivation of nonnutritive sucking in calves, Bos taurus. Anim. Behav. 49:1503-1510.
Siegel, S., and N. J. Castellan. 1988. Nonparametric Statistics for the Behavioural Sciences. 2nd ed. McGraw-Hill, New York.

Spoolder, H. A. M., S. A. Edwards, and S. Corning. 1999. Effects of group size and feeder space allowance on welfare in finishing pigs. Anim. Sci. 69:481-489.

Svensson, C., K. Lundberg, U. Emanuelson, and S. O. Olsson. 2003. Morbidity in Swedish dairy calves from birth to 90 days of age and individual calf-level risk factors for infectious diseases. Prev. Vet. Med. 58:179-197.

Turner, S. P., A. G. Sinclair, and S. A. Edwards. 2000. The interaction of liveweight and the degree of competition on drinking behavior in growing pigs at different groups sizes. Appl. Anim. Behav. Sci. 67:321-334. 